\title{
Mapeando o Corpo: proposições práticas para a partilha do sensível nas representações do corpo em criação
}

Body Mapping: practical propositions for sharing the sensitive in the body's representation for creative

processes

Adriana Miranda da Cunha ${ }^{1}$ 


\section{Resumo}

O mapeando o corpo é uma abordagem/prática sobre o corpo vinda da cognição incorporada largamente utilizada na neurociência e na psicanálise. No entanto, há vestígios vigorosos que demonstram que esta abordagem específica de mapeamento corporal, se associada aos (des)envolvimentos da performance, pode oferecer proposições instigantes para desdobrar possibilidades de representação dos afetos e da partilha do sensível nos processos de criação de obras artísticas. Aqui exploraremos dois casos para análise do mapeando: utilizado como ponto de partida investigativa e temática sob o olhar da criadora sul-africana Sara Matchett na performance Washa-Mollo (2009) e Walk: South Africa (2013); e como instrumento dialógico para a partilha do sensível e para a criação de relações comunitárias na experiência do projeto Volume 44, coordenado pela antropóloga luso-moçambicana Elsa Oliveira. Por sua natureza cartográfica, o mapeando o corpo facilita a arqueologia corporal desvendando topografias simbólicas, possibilitando o acesso à um tipo de registro sistêmico: a dos arquivos corporais ligados à materialidade e à imaterialidade do(s) corpo(s) engajados em criação.

Palavras-chave: Mapeando o corpo; partilha do sensível; processos criativos.

\section{Abstract}

The body mapping is an approach/ practice about the body coming from the embodied cognition studies widely used in neuroscience and psychoanalysis. However, there are strong traces demonstrating that this specific approach of mapping the body associated with performance studies, may offer compelling propositions to unfold representations of the affections and possibilities of sharing the sensitive in the creative processes. Here, we explore two cases of the body mapping: used as a starting point for thematic research under the gaze of the South African director Sara Matchett in the performance Washa Mollo (2009) and Walk: South Africa (2013); and as a dialogic tool for sharing the sensitive and building community in the project Volume 44, coordinated by the PortugueseMozambican anthropologist Elsa Oliveira. For its cartographic nature, the body mapping facilitates the archaeological register and the creation of a symbolic body topography, allowing access to a kind of systematic register: that of the body archives linked to the history of its material and immaterial representations of body(ies) engaged in creative processes.

Keywords: Body mapping; sharing of sensitive; creative processes. 
Como mapear "etologicamente" os afectos de uma pessoa? (Pelbart, 2008, p.1)

Eu parto das experiências vividas na África do Sul, mais precisamente em contato com a criadora de cena sul-africana Sara Matchett ${ }^{2}$, diretora do projeto The Mothertongue 3 (University of Cape Town) que desenvolve performances que tocam questões de gênero; e, com a pensadora do corpo luso-moçambicana Elsa Oliveira ${ }^{4}$, antropóloga e pesquisadora do African Centre for Migration and Society (ACMS - Wits University), também coordenadora do projeto Volume $44^{5}$ que usa arte como ação de intervenção junto à migrantes africanos(as) trabalhadores(as) do sexo. Identifico vestígios instigantes em seus trabalhos relacionando-os com as ideias sobre a partilha do sensível de Jaques Rancière; ideias sobre afeto de Gille Deleuze e Peter Pal Pelbart; e, sobre os arquivos do corpo de André Lepecki com o que as criadoras em questão apontam como sendo uma prática chamada mapeando o corpo ${ }^{6}$, que é uma metodologia da cognição incorporada que atualmente tem seu foco mais voltado para o campo terapêutico, na psicanálise e na neurociência. Porém, as perspectivas supracitadas, em fricção com o campo da performance, tecem com o "mapeando"7 uma possibilidade vigorosa de acesso às topografias simbólicas do corpo com o intuito de criação de obras artísticas. Portanto, pretendo aqui indicar caminhos do mapeando o corpo como uma prática potente de acesso aos arquivos corporais ligada aos processos de criação vislumbrando explorar as possibilidades de uma sistematização, e, simultaneamente, dar ênfase nos seus sentidos enquanto arte política.

A dialética relação entre a estética e a política que o filósofo franco-argelino Jaques Rancière estabelece em suas análises para falar de arte, estabelece também seu jogo filosófico com diretrizes precisas sobre a questão da democracia, ou seja, sobre o sentido do comum, da partilha do sensível e do tolerável/intolerável nas representações das sociedades modernas ocidentais. Estas orientações, marcantes em seu pensamento, me foram caras ao analisar aqui a prática em questão, o mapeando o corpo, como uma possível abordagem de construção de espaços dialógicos que se utilizam da estética para o desenvolvimento do pensamento crítico acerca da representação do corpo. A ideia da criação de metonímias do corpo, do mapeamento de seus afetos e memórias, e de partilhas do material mapeado como força convergente para discussões sobre as políticas do corpo, são o centro de atenção nas próximas análises do presente texto.

Entender o corpo como um território possível de criação de topografias internas e externas, de conexões, desconexões, caminhos, meridianos, constelações, totalidades, vazios, cicatrizes, acumulações, ossos quebrados, articulações, centros de

\footnotetext{
2 Sara Matchett é pesquisadora, performer e professora da University of Cape Town no Departamento de Arte - Drama. Coordena o projeto The Mothertongue, sediado na Cidade do Cabo e formado em 2000 por mulheres da África setentrional sediadas na Cidade do Cabo, que investiga violência de gênero em centros urbanos e rurais e atua como plataforma de educação e ativismo de gênero.

3 http://mothertongue.co.za/The Mothertongue Project/Home.html

4 Elsa Oliveira é antropóloga sediada na Wits University no African Centre for Migration and Society (ACMS) e desenvolve pesquisa com trabalhadores do sexo (mulheres e homens transgênero), migração, saúde, direitos humanos. Coordena o projeto Volume 44 que investiga as jornadas de migração de trabalhadores do sexo usando arte como forma de pesquisa.

5 http://www.migration.org.za/page/posters-vol44/move

6 Traduzido de body mapping.

7 Apelido carinhoso aqui dado por mim nas práticas durante o mestrado, fora e dentro da academia, na África do Sul e no Brasil, que não estão inclusas nas reflexões deste artigo.
} 
força, traumas, fortalezas, dores, etecetera, pode ser uma estratégia fértil no desenvolvimento de processos de criação. Essa dinâmica topográfica que envolve o mapeando, de acordo com Sandra Blakeslee, é aberta, no sentido de que pode ser aplicada em vários campos de teorias do corpo-mente devido à sua natureza interdisciplinar e prática: "Mapas corporais fornecem uma valiosa lente para a análise enquanto espécie humana e enquanto indivíduos" (Blakeslee, 2007, p.5). Entretanto, apesar desta importante contribuição a autora, em localizando a prática a partir da neurociência com base epistemológica na biologia, acaba por limitar sua potência. Buscando explicitar perspectivas filosóficas mais amplas e transversais, aqui, pretendo associar a abordagem cartográfica/processual do mapeando aos estudos da performance, imersa nas experiências das duas criadoras africanas, onde identifiquei uma grande potência de ação teórica e abertura prática para o mapeando o corpo.

Quando Pelbart escolhe a palavra "etologicamente" sobre a questão "como mapear o corpo?", ele nos convida a pensar (também) sobre questões de comportamento. Neste aspecto, a cognição incorporada pode oferecer uma luz, já que é um dos ramos de estudos da neurociência, que investiga as relações entre o corpo, a mente e seus processos de significação associados à experiência vivida do(a) sujeito(a) e ao comportamento. Tais processos de significação podem estar associados tanto em contextos que se estabelecem externamente ao corpo (sejam eles de ordem social ou cultural), quanto ao processos internos do(a) sujeito(a) (ligados aos seus processos cognitivos). A investigação, de acordo com os estudos sobre a cognição incorporada, acontece a partir dos desdobramentos dos processos de criação, apropriação, reprodução e procriação dos movimentos e dos gestos, e suas associações com sistemas de valores e crenças. Dialeticamente, a cognição incorporada interessa-se também pelos gestos humanos como variantes das impressões afetivas do/no corpo e suas linguagens expressivas (Wilson, 2001; Blakeslee, 2007). A cognição incorporada lança-se como uma forma de aquisição de conhecimentos que se relacionam com as camadas mais internas da memória corporal.

O mapeando o corpo, em sendo uma abordagem inserida nos estudos da cognição incorporada, a priori, trata-se de uma forma de mapeamento razoavelmente simples, onde o corpo (do(a) sujeito(a) ou do objeto de pesquisa) é desenhado e auto representado numa ampla folha de papel, e recebe uma linha de contorno simbólica definindo espaços para um registro posterior processual detalhado de mapeamento. O foco do trabalho determina o processo no qual este espaço simbólico será preenchido, ou seja, no campo da psicanálise, por exemplo, onde esta abordagem é mais utilizada, esta fase talvez seja a mais importante pois gera informações relevantes sobre o material individual - sobre o indivíduo e sobre sua inter-relação. Já nos casos aqui analisados, as criadoras utilizaram-se de formas distintas de ativação da memória corporal para preenchimento dos mapas (falaremos sobre cada caso e sua abordagem particular de ativação da memória). O processo de desenhar-se, por si só, desencadeia um "pensar-se distanciado", sugerindo à organização arquivista da memória corporal, procedimentos de estranhamento uma vez que a auto representação requer um conjunto de decisões para tal arranjo. Perguntas repetem-se frequentemente quando vem o pedido para desenhar o (seu) corpo: como fazer isso? Neste sentido, a potência do pensar sobre si mesmo, sobre como representar-se num con- 
torno específico em forma de imagem desenhada, desdobra-se na criação subjetiva da ação de desenhar-se, antes mesmo de começar o processo de mapeamento de sua história.

A partir do desenho de si, o(a) criador(a) pode, por meio de técnicas de toque, massagem, visualização, contação de histórias (do todo ou de partes do corpo), dança, movimento, etecetera, trabalhar a ativação da memória para o preenchimento deste mapa, contemplando uma arqueologia corporal, detectando lugares de potência de ação positiva ou negativa em seu corpo. Seria uma espécie de processo de arquivamento de afetos.

Nas obras aqui analisadas, esta imagem/processo de mapeamento, no entanto, não intenciona evocar uma duplicidade representativa do corpo do(a) criador(a), mas gerar "uma imagem concebida como operação de uma arte" (Rancière, 2010, p.103), onde o processo de mapeamento evidencia a história material e imaterial daquele(s) corpo(s). Mais do que evidenciar, produz topografias que localizam de forma precisa a sua história numa espécie de alteridade do corpo sobre ele mesmo. É interessante observar como as duas criadoras utilizaram-se da abordagem para o desenvolvimento de seus trabalhos. Estes espaços de topografias simbólicas, zonas de demarcação, partes de dentro e de fora, áreas de foco e de rarefação, permitem que se possa delinear e visualizar a materialidade e imaterialidade dos arquivos do corpo, as memórias que conceberam cicatrizes visíveis ou invisíveis. Este material contido no corpo, uma vez mapeado, torna-se uma fonte vigorosa de criação.

Assim, em contraponto à abordagem ligada a visão da neurociência e da biologia, alinho pensamentos da filosofia do corpo e da performance para aproveitar o mapeando como potência criadora nas experiências dos casos apresentados. $O$ mapeando do corpo, aqui, encontra-se alocado no campo da corporeidade e da performance, e a abordagem assume um perfil mais de prática - é desenvolvido pela auto representação, porém, através de/combinada com técnicas corporais com foco na ativação da memória corporal para criação de cena; criação de sentido de comunidade através da partilha do sensível; e, arquivamento de afetos no corpo do criador.

\section{A partilha do sensível}

A arte e a estética contém em si formas de subjetivação capazes de nos tornar sensíveis aos aspectos da realidade não facilmente percebidos. De acordo com Rancière, na expressão partilha do sensível estaria contida "a chave da junção necessária das práticas estéticas e práticas políticas" (Rancière, 2005, p. 15) para que se possa definir um contorno possível do que seja o comum partilhado numa abordagem crítica e política. Na partilha do sensível se estabelece a divisão:

[...] dos espaços, dos tempos e tipos de atividades que determinam propriamente a maneira como um comum se presta à participação e como uns e outros tomam parte nesta partilha. [...] Ter esta ou aquela ocupação define quem tem competência ou incompetência para o comum. [...] É um recorte dos tempos e dos espaços, do visível e do invisível, da palavra e do ruído que define ao mesmo tempo o lugar e o que está em jogo na política como forma de experiência. (Rancière, 2005, p.15-16). 
Rancière preocupa-se com os planos, ou, paradigmas da superfície de significados dos signos e formas, e vê neles toda a lógica política da partilha do que considera sensível $^{8}$. A partilha não acontece sem sua dimensão política, e é na partilha que a política dos homens se justifica. No entanto, a política independe dos homens (indivíduos), ela existe na dialética e na ética intermitente nos jogos de poder (do coletivo) para determinar a partilha. Os signos e suas formas, portanto, seriam portadores de figuras de comunidade que se modificam ou adequam de acordo com o contexto ao qual pertencem.

Se as análises sobre a partilha do sensível são diretamente relacionadas às estruturas políticas nas quais definem a sociedade em que vivemos, e se toda a ação estética e artística tem um efeito político, seja ele crítico/ativo ou alienante/passivo dentro das escolhas cotidianas que assolam os(as) artistas, pensar abordagens que ofereçam uma plataforma de organização sistêmica do sensível "no corpo" para a cena, parece relevante no processo de criação de uma obra. Dentro deste pensamento, o mapeando o corpo, em sendo uma prática de registro cartográfico afetivo de materiais sensíveis do corpo do criador, torna-se uma ferramenta política preciosa num processo de criação. Assim, ele é explorado aqui como uma prática metodológica de organização de materialidades e imaterialidades - individuais e coletivas - para processos artísticos, cada caso analisado com um perfil específico da prática em si.

\section{Sobre afetos e arquivos corporais}

As análises discorridas por Deleuze e Pelbart sobre o complexo caráter dos afetos no corpo - sua impermanência e oscilação, sua ligação direta com o grau de potência de afetar e ser afetado de acordo com a história material e imaterial de cada indivíduo - sugerem contornos possíveis onde sua definição possa ser pensada. "Não sabemos ainda o que pode o corpo, seria preciso fazer para cada animal verdadeiros mapas de afetos" (Deleuze apud Pelbart, 1978, p.2). Perlbart afirma:

\footnotetext{
Vamos aprendendo a selecionar o que convém com o nosso corpo, o que não convém, o que com ele se compõe, o que tende a decompô-lo, o que aumenta sua força de existir, o que a diminui, o que aumenta sua potência de agir, o que a diminui, e, por conseguinte, o que resulta em alegria, ou tristeza. (Pelbart, 2008, p.1)
}

A partir disso, penso que o corpo seria o santuário dos afetos, inesgotável até sua morte, e carregaria em si um arcabouço de memórias, histórias, sentimentos, cicatrizes, traumas, dores, amores constituindo uma fortaleza de cognições que conectam correntes elétricas continuas de alegrias e tristezas. Uma fonte arqueológica de afetos que resultam na própria variação ligada à potência de agir.

Já sob as perspectivas relacional e temporal de revisitação das memórias do corpo, do movimento e das criações artísticas, André Lepecki nos traz o conceito de corpo arquivo quando analisa as razões pelas quais há recriações (re-enactments) de obras. Lepecki fala sobre os materiais que ainda podem ser explorados no presen-

8 A saber "atos estéticos como configurações da experiência, que ensejam novos modos de sentir e induzem novas formas de subjetividade política" (Rancière, 2005, p.11). 
te a partir de criações feitas uma vez no passado. Ele usa a imagem do "voltar cada vez mais sobre seu próprio rastro" para abordar o "retorno como experimentação", como uma manifestação do "impulso arquivista" (Lepecki, 2013, p.1-2), mais especificamente ligado à dança, o impulso de revistar a memória para questionar a própria natureza do arquivo, segundo ele, um dispositivo foucaultiano de "distribuir o visível e o invisivel e fazer nascer ou desaparecer o objeto que não existe sem ele" (Lepecki, 2013, p.3). Esta ideia de arquivo que se localiza num corpo-obra-tempo-espaço, que ele associa com formas de "desbloquear, liberar e atualizar as numerosas possibilidades e impossibilidades virtuais de uma obra" (Lepecki, 2013 pg.5), possibilidades e impossibilidades que se mantém num estado de reserva do devir de encarnação, também trazem a perspectiva do corpo como um arquivo, ou o corpo seria um arquivo e o arquivo seria um corpo. O corpo nos reserva um grande número de meticulosas conexões, conscientes e/ou inconscientes, afloradas ou não, voluntárias ou não, que nos conduzem através das experiências vividas para sinopses ininterruptas de apropriações cognitivas e afetivas.

Nos casos da criadora Sara Matchett em suas performances, e da pesquisadora Elsa Oliveira no projeto Volume 44, a organização sistêmica das histórias contidas nos corpos dos participantes, operou simultaneamente como um procedimento arquivista do material sensível sobre a temática artística, e como ferramenta de construção de sentido de comunidade através da partilha deste material. A possibilidade de troca de configurações arqueológicas dos afetos dos participantes, que espelham realidades dissonantes, tornou-se um aspecto profundamente ligado ao teor político e social dos trabalhos.

\section{Caso 1: Sara Matchett e o Mothertongue Project}

Uma primeira pista de investigação do mapeando o corpo como uma prática de criação surgiu em entrevista ${ }^{10}$ concedida por Sara Matchett em 2014, performercriadora sul-africana e diretora do projeto The Mothertongue, que trabalha de forma colaborativa com intérpretes-criadoras da Zâmbia e Tanzânia. Matchett busca em seus cruzamentos experimentais entre teatro, dança, performance e cura, processos somáticos de mapeamentos corporais para encontrar as paisagens textuais de sua performance Washa-Mollo ${ }^{11}$ (2009) e Walk: South Africa ${ }^{12}$ (2013). Desde de 2000, Matchett vem utilizando-se de técnicas sobrepostas de mapeamento (mapeando seu corpo, o corpo do outro, e suas jornadas) para criação performática, e frequentemente descobrindo estruturas arqueológicas diversas em seu próprio corpo.

O mapeando o corpo, para a diretora, serve como um ponto "político" de partida que alimenta a organização cartográfica dentro da jornada investigativa e temá-

\footnotetext{
9 Tradução minha de vuelven cada véz más sobre su proprio rastro.

10 Entrevista concedida em setembro de 2014, via Skype, para alunos do curso de mestrado em Teatro Aplicado, da Wits School of Art (WSOA), na disciplina de Teatro como Educação, Ativismo e Terapia (Theatre as Education, Activism and Therapy), ministrado pela professora Cherae Halley.

11 Washa-Mollo: performance colaborativa autobiográfica desenvolvida pelas integrantes do Mothertongue Project, dirigida por Sara Matchett e Makgathi Mokwena. A performance foi inspirada em pesquisas sobre violência de gênero e a cultura do estupro nas comunidades rurais e townships (favelas) da África do Sul, usando o mapeando o corpo como ponto de partida investigativo com as vítimas.

12 Walk: South Africa: performance inspirada na peça da autora indiana Maya Krishna Rao's "The Walk", criada em resposta ao estupro coletivo de Jyoti Pandey dentro de um ônibus em Delhi - Índia em 2012. Walk: South Africa foi criada em resposta ao estupro coletivo seguido de morte de Anene Booysen em Western Cape - África do Sul em 2013.
} 
tica junto aos grupos de mulheres com os quais interage. Por meio de focalizações, contação de histórias, e os autorretratos representacionais do mapeando, Matchett coleta dados sobre as memórias e afetos arquivados nos corpos das mulheres que sofreram abuso e violência sexual. Este processo, no entanto, não se vê esvaziado de significado para as participantes, pois ela procura trazer aspectos relevantes acerca das políticas do corpo fazendo com que a facilitação seja além de coleta de dados para sua investigação artística, um encontro de cura e apoio mútuo entre as mulheres que sofreram tais violências. Engajada em sessões diversas de revisitação das experiências vividas para a ativação da memória, descrições detalhadas das histórias, das sensações corporais, registros de dor, de sentimentos localizados em partes específicas nos seus corpos, reflexões sobre os eventos, ela trabalha a prática do mapeando repetidamente com estas mulheres, e posteriormente, investiga os espaços e sensações mapeadas em seu próprio corpo. Justapondo este estudo em seu corpo vocal, encontra assim combinações da geografia arquivista do trauma que ela cria em seu próprio mapa, por meio das investigações ocorridas nos encontros.

Há um jogo de alteridade nos dispositivos construídos pela performer, que busca na "outra" lugares desconhecidos em si, bem como o apoio nas relações comuns como uma espécie de espelhamento e apropriação. O resultado deste processo permite à performer encontrar reverberações e concavidades com sonoridades múltiplas em seu corpo. Em entrevista, Matchett afirmou que descobriu em seu corpo lugares nunca antes conhecidos, que pelo processo de mapeamento corporal e alteridade conseguiu chegar a locais internos que de outra forma não conseguiria, pois foi no trajeto do trauma no corpo da outra, que ela pode construir trajetos em lugares antes desabitados em seu corpo.

Como resultado, na performance Walk: South Africa Matchett nos convidou a trilhar um caminho itinerante onde o público atravessou as premissas externas e internas do Wits Theatre, e nos diferentes espaços estéticos aconteceram cenas distintas, com distintas atrizes e ambientação, numa procissão teatral. A cena final, já dentro do teatro, Matchett encontrava-se sozinha no palco. Ela propõe um passeio através de sua voz modulando imagens ora de ancestralidade por meio de cânticos tradicionais africanos, ora por meio de ruídos de dor, ora de sons animalescos, culminando num conjunto de sons guturais transitórios inidentificáveis criando uma espécie de distanciamento da própria condição humana do corpo em cena ${ }^{13}$. Há momentos em que seu corpo-voz-expressão se tornam tão alterados que suscitam uma espécie de empatia sensorial pela sua intolerabilidade. A sensação de dor e violência tornam-se palpáveis no corpo do espectador ${ }^{14}$. Seu forte trabalho de respiração pranayama ${ }^{15}$ auxilia a transformação de sua máscara facial, o que enfatiza a dinâmica de distanciamento entre o corpo da performer e o corpo de um ser humanamente repulsivo.

Poderíamos aqui, fazer menção aos questionamentos sobre o intolerável da imagem, que "o que ela mostra é demasiado real" (Rancière, 2010, p.125). A questão da violação do corpo de mulheres da África setentrional principalmente em discus-

13 Aqui, um trecho editado e fragmentado da obra https://www.youtube.com/watch?v=SbEXlhtl cU

$14 \mathrm{Eu}$, como espectadora, senti dor angustiante durante a apresentação. Posteriormente, tanto na conversa com o público no pós-apresentação, como no debate com colegas mestrandos em sala de aula, houveram depoimentos que se assemelharam ao meu, de sensação palpável de dor no corpo durante a performance de Matchett.

15 Conjunto de técnicas de respiração do yoga (Matchett, 2013, p.108) utilizadas pela performer. 
sões ligadas a alguns aspectos da sexualidade do homem africano, se esconde atrás de questões complexas de algumas tradições tribais de raízes profundamente patriarcais. São grandes as contradições em relação ao debate que envolve casos extremos do ativismo anticolonialista, que pode cumprir um papel controverso na dogmatização da "cultura do estupro" ao tentar justificar o comportamento desumano e machista de muitos homens que circulam entre os centros urbanos e rurais daqueles países. Há uma tensão social que opera contra a imposição de valores ocidentais monogâmicos a partir da colonização. Algumas vertentes desta resistência, acabam por distorcer a ideia da sexualidade africana poligâmica com intuito de amenizar a compreensão da violência doméstica, podendo ser interpretado como a "normalização" do estupro, a priori, no mundo privado, se estendendo também à esfera pública por meio das relações de poder, principalmente na família e na religião (Rasool, 2012). 0 direito de escolha ao sexo da mulher negra com menos acesso à educação é ligado às questões complexas das tradições da sexualidade em tais instituições, gerando dinâmicas sociais de terrível estigma caso as mulheres denunciem seus violadores.

Neste sentido, a evocação coletiva dos traumas, direcionada numa perspectiva ativista de gênero, permite que a facilitação em grupo seja também uma potência de ação educativa principalmente para as mulheres que vivem nas zonas rurais e sentem-se limitadas diante das questões culturais do patriarcado. Participantes demonstraram repensar sobre os limites de seu corpo e sobre as dinâmicas de alguns ritos de sexualidade que lhes ferem e desonram. Ainda, diante das estatísticas alarmantes das pesquisas ligadas à transmissão do vírus HIV na África do Sul ${ }^{16}$, mulheres, principalmente jovens e virgens, têm seus corpos violados não apenas pela brutalidade da situação em si, mas também pelas marcas definitivas deixadas por conta da transmissão do vírus durante o ato, dinâmica que vem se repetindo desde sua aparição a partir dos anos 1980.

Questões de violência de gênero são relevantes no trabalho de Matchett, que, em suas performances, explora através de imagens em seu corpo os lugares de dor e de inconformismo que envolvem o estupro, principalmente o coletivo e o corretivo.

\section{Caso 2: Projeto volume 44}

A segunda pista que demonstrou a potência de ação do mapeando se apresenta quando em contato com o Projeto Volume 44, coordenado pela antropóloga lusomoçambicana Elsa Oliveira, que investigou as histórias de migrantes africanos, em sua maioria transgêneros e trabalhadores(as) do sexo que vivem no bairro de Hillbrow ${ }^{17}$, localizado na cidade de Johanesburgo. O projeto teve um forte cunho social e visou buscar formas de visibilidade da luta para a descriminalização do trabalho

\footnotetext{
$16 \mathrm{Na}$ África do Sul o percentual da transmissão do vírus HIV chega a aproximar-se à 48\% em algumas cidades, como Johanesburgo. Disponível em: www.avert. co.za. Acesso: 7 agosto de 2015.

17 Bairro situado nas proximidades do centro cidade de Johannesburgo, que possui uma configuração peculiar, sendo local de residências de pessoas de cor branca durante o regime político apartheid (1948-1990), e depois de sua queda, passou por inúmeras transformações. O bairro hoje é conhecido por abrigar em sua maioria migrantes do continente africano e pelo alto nível de abandono político, violência, drogadição, trabalho ilegal e exploração sexuais, xenofobia e extrema desigualdade.
} 
sexual no país ${ }^{18}$. O projeto engajou-se com abordagens participativas baseadas em arte associadas ao mapeando, e utilizou-se da transdisciplinaridade como estratégia de ação: fotografia, vídeos e escrita criativa.

O Volume 44 acabou desdobrando-se numa série de ações em centros urbanos e rurais ${ }^{19}$ sul-africanos, e explorou o mapeando do corpo como uma plataforma evocativa de socialização de histórias do corpo dando ênfase na construção de senso de comunidade junto aos participantes. Contudo, o conceito comunidade neste projeto abarca a diversidade com ponto de partida, sob ótica ontológica onde "a comunidade hoje só é pensável enquanto negação da fusão, da homogeneidade, da identidade consigo mesma" (Pelbart, 2013, p. 5). Portanto, tal paradigma de comunidade oferece uma plataforma adequada em relação ao perfil heterogêneo e plural dos grupos aos quais o projeto se relaciona.

Há um fluxo de centenas de migrantes que chegam em Park Station ${ }^{20}$ diariamente. Até o ano de 2013, a África do Sul era o maior destino de migrantes do mundo resultando num enorme impacto social. Johanesburgo abriga africanos vindos de países vizinhos que enfrentam continuadas guerras civis, do centro e sul continental, atingindo níveis de superpopulação nos bairros mais pobres. Por consequência, nos anos de 2008, 2013 e 2015 houveram ondas crescentes de ataques xenofóbicos.

A África do Sul foi, até o ano passado, o maior destino de exilados do mundo; Johanesburgo tem sido o centro desta migração. Em 2008, a violência contra imigrantes se espalhou nas favelas, periferias urbanas, no centro da cidade de Johanesburgo, e pelo país. No geral, mais de 60 pessoas foram assassinadas, 700 feridas e 100.000 desabrigadas ${ }^{21}$ (Wilhelm-Solomon, 2013, p.41).

A migração massiva de africanos, dinâmica que nos últimos três anos tomou proporções maiores na mídia internacional, já era uma questão capital para os controles institucionais de fronteira e circulação. Oliveira vem desenvolvendo trabalhos de pesquisa e inclusão de migrantes transexuais desde 2010. Para coletar dados sobre as jornadas destas mulheres e homens desde suas terras-mães até a chegada à Hillbrow, o mapeando o corpo, neste projeto, funcionou como plataforma de registro de material sensível construído nos processos artísticos transdisciplinares, bem como registro de seus cotidianos, desejos e inspirações durante workshops que duraram dias. Os facilitadores utilizaram-se do mapeando como ação convergente da fotografia e da escrita criativa para a ativação da memória dos participantes. A contação de histórias de partes do corpo, por exemplo, facilitou a partilha das histórias de forma processual até chegar à construção do corpo como um todo, focando na partilha do material de subjetivação de cada participante como forma de estabelecimento de confiança entre o grupo. A construção do comum, aqui, refere-se às "formas de

\footnotetext{
18 No continente africano, o trabalho sexual é crime, e os trabalhadores sexuais raramente possuem acesso às estruturas de saúde. Este fato é complexificado pela condição extrema da transmissão do vírus HIV, e o pouco, ou falta de acesso aos antirretrovirais. Organizações Não-Governamentais e pesquisadores, no entanto, lutam arduamente para mudar este quadro, buscando formas de acesso aos trabalhadores às políticas de saúde, bem como dar fim da repressão policial. 19 O ACMS, departamento ao qual Oliveira é associada, monitora de perto a circulação da população urbana e rural no país, e investiga os impactos gerados por tal dinâmica. As relações econômicas e culturais são muito moldadas pelas rotas internas de migração, principalmente indígena, em busca de trabalho e subsistência familiar. Disponível em: http://www.wits.ac.za/acms/ ou http://www.migration.org.zal

20 Estação central que recebe o fluxo de ônibus e trens internacional e interdistrital.

21 Tradução minha: "South Africa was, until last year, the largest recipient of asylum seekers in the world; Johannesburg has been the centre of this migration. In 2008 anti-immigrant violence spread from the townships on the urban peripheries to the inner city of Johannesburg and around the country. Overall more than 60 people were murdered, 700 wounded and more than 100000 displaced".
} 
inscrição do sentido de comunidade, [que] definem como as obras e performances fazem política" (Rancière, 2005 pg. 18).

O material sensível identificado como histórias daqueles participantes, contam mais do que casos pessoais, contam sobre sistemas políticos que limitam a vida social dos que escolhem viver de acordo com sua natureza não condizente com os parâmetros de normalidade de gênero em suas sociedades. Em muitos casos, os participantes corriam risco extremo de vida em seus países de origem. Em alguns dos países africanos vizinhos, a transexualidade é crime, e seu controle é uma prática social feita pelos próprios cidadãos "normatizantes" - aqueles que ajudam no controle dos espaços públicos e privados - principalmente a família e os núcleos religiosos que supostamente "carregam tal vergonha". A transexualidade na África do Sul é protegida por lei, por isso, muitos dos homens e mulheres transgêneros migram para 0 país, sem, no entanto, contar com políticas integrativas e acabam tornando-se trabaIhadores(as) do sexo, atividade proibida por lei, permanecendo ainda às margens da legalidade (Wilhelm-Solomon, 2016).

Os mapas feitos pelos participantes foram, desde o início, tratados como obras de arte. Foram desenvolvidos em grande telas com tinta acrílica, extremamente elaborados, detalhados por símbolos e trechos dos textos produzidos em encontros de escrita criativa, muito ricos em cores. Os mapas corporais foram exibidos ${ }^{22}$ no Market Theatre Photo Workshop, um conceituado e antigo espaço de arte, com a presença dos migrantes/trabalhadores do sexo/artistas numa apropriação de suas próprias memórias e histórias ligadas ao orgulho (proud) daqueles corpos/obras expostos, que, simultaneamente, estavam presentes na noite de abertura da exibição. Presentificando a obra e os autores, testemunhas vivas das histórias, representou-se um território arqueológico das memórias comuns daqueles(as) sujeitos(as).

Esse comum passa hoje pelo bios social propriamente dito, pelo agenciamento vital, material e imaterial, biofísico e semiótico, que constitui hoje o núcleo da produção econômica mas também da produção de vida comum. (Pelbart, 2013, p.4).

Na noite de abertura da exibição, a presença dos participantes poderia ser lida como duplamente intolerável - por serem migrantes ilegais que buscam asilo para poder escapar das perseguições políticas e homofobia em seus países de origem, e por serem trabalhadores do sexo, atividade proibida e estigmatizada na África do Sul. A exibição, no entanto, convida à fruição dos espectadores, e mais precisamente às autoridades que lidam com as questões delicadas de direitos humanos, saúde e bem estar social a operarem em concordância com as solicitações do grupo, que tornou-se uma Organização Não-Governamental (ONG) de suporte às pessoas que encontram-se na mesma situação. O trabalho teve uma grande repercussão, e segue em pesquisa e intervenção, inclusive com a publicação de livros e campanhas. Assim, a produção de vida comum configurou-se durante o projeto como uma condição de potência de produção de realidades, mediante as demandas encontradas durante o mapeamento de seus corpos/vidas. Por meio do Volume 44, o grupo passou a ver-se como comunidade oferecendo, inclusive, apoio aos outros(as) iguais em exclusão.

22 Queers crossing: a participatory arts-based project https://issuu.com/move.methods.visual.explore/stacks/38e6796bbfaf4c2dba130c9820cd0184 
Segundo Pelbart, sobre o comum:

Seria o caso de postular o comum mais como premissa do que como promessa, mais como um reservatório compartilhado, feito de multiplicidade e singularidade, do que como uma unidade atual compartida, mais como uma virtualidade já real do que como uma unidade ideal perdida ou futura. (Virno apud Pelbart, 2008, p.4).

Neste sentido, o mapeando o corpo foi utilizado como um elo de ligação do comum nas histórias do(as) migrantes trabalhadores do sexo, em vista de criar uma obra capaz de condensar múltiplas prerrogativas: a obra como processo de experimentação e investigação participativa individual e coletiva; como estandarte de uma causa; como registro antropológico vigoroso de histórias e arquivos; como território de partilha; e finalmente como ferramenta de empoderamento e cura dos participantes.

\section{Considerações Finais}

Nesta organização escrita de materiais colhidos sobre a prática do mapeando o corpo ao longo da experiência vivida na África do Sul, pretendi fazer uma reflexão sistemática. Penso que há uma grande relevância nesta forma operacional e metodológica para trabalhos de criação artística, mais precisamente em processo de criação de performance. A prática, como aqui chamo, apesar de ter sua principal ação no campo da cognição incorporada, demonstra ser uma abordagem vigorosa, tendo como base teorias que tocam na questão dos afetos do corpo, do corpo como um manancial arqueológico de memórias, e de construção de arquivos ligados ao material sensível a ser partilhado. A partilha do sensível torna-se, por meio do mapeando, um caminho possível de construção de diálogos políticos sobre o corpo, podendo também ser uma ponte de ligação entre criadores para construção de espaços comuns, ou de mediação de espaços de diferença. O mapeamento corporal nos parece ser uma rica fonte a ser explorada por criadores de cena.

\section{Referências}

BLAKESLEE, Sandra; BLAKESLEE, Matthew. The body has a mind its own: how body maps in your brain help you do (almost) everything better. New York: Random House, 2007.

DELEUZE, Gille. Deleuze/Spinoza, Cours Vincennes-24/01/1978 Les Cours de Gilles Deleuze, 1978. Disponível em:

http://www.webdeleuze.com/php/texte.php?cle=194\&groupe=Spinoza\&langue $=5$

LEPECKI, André. El cuerpo como archive: el deseo de recreación y las supervivências de las danzas. In: NAVERÁN, Isabel; ÉLIJA, Amparo (Org.). Lecturas sobre Danza y Coreografia. Madrid: Artea Editorial, 2013.

MATCHETT, Sara; MOKWENA, Makgathi. Washa Mollo: Theatre as a Milieu for Con- 
versations and Healing. Cape Town: Matatu, 2013, 44: 107.

PELBART, Peter Pál. Elementos para uma cartografia da grupalidade. Próximo ato: questões da teatralidade contemporânea. São Paulo: Itaú Cultural (2008), p. 33-37.

RANCIĖRE, Jacques. A partilha do sensível: estética e política. Tradução Monica Costa Neto. São Paulo: EXO experimental organização Ed 34, 2005.

RANCIĖRE, Jacques. El espectador emancipado. 1ํeㄹção. Buenos Aires: Manancial, 2010.

RASOOL, Shahana. Do we accept the unacceptable? The privatization of women Abuse by informal network in South Africa. Journal of gender and religion. In: Africa, Vol $18, \mathrm{n} \times 2,2012$.

WILHELM-SOLOMON, Matthew. Seeing sex workers through stories. In: OLIVEIRA, Elsa; VEAREY, Jo. Iziwi Lethu: a participatory arts-based project. The MoVE project: African Centre for Migration and Society: University of Witwatersrand, 2016.

WILHELM-SOLOMON, Matthew. Writing invisbility: conversations on the hidden city. Johannesburg: Mail \& Guardian and ACMS, 2013. Disponível em :

http://www.mmg.mpg.de/fileadmin/user_upload/Subsites/South_Africa/migration_ nu3a.pdf

WILSON, Margaret. Six views of embodied cognition. University of California. Psychonomic Bulletin \& Review, 2002. Disponível em: http://link.springer.com/article/10.3758/BF03196322

Recebido em: 30/09/2016

Aprovado em: 11/11/2016 